\title{
"Dizem-Me que sou louco" - AS EPISTEMOLOGIAS POÉTICAS DE Baudelaire e Benjamin
}

\section{Georg Otte}

- (BENJAMIN, Walter. Briefe. Org. e notas de Gershom Scholem e Theodor W. Adorno. Frankfurt/M.: Suhrkamp, 1966: 783. Trad. nossa.)

["Es werden Motive versammelt, aber nicht durchgeführt."] (lbid.)

- (BENJAMIN, W. Passagens. Organização Willi Bolle; colaboração na organização Olgária Chain Féres Matos; tradução do alemão Irene Aron; tradução do francês Cleonice Paes Barreto Mourão. Belo Horizonte: Editora UFMG; São Paulo: Imprensa Oficial do Estado de São Paulo, 2006: 502.)

- (ADORNO, Theodor W. Notas de Literatura. São Paulo: Editora 34: 2003: 1545.)

-(BENJAMIN, W. Briefe. Op. cit.: 786.$)$
Numa carta de 10 de novembro de 1938 a Benjamin, Adorno fala de uma "certa decepção"* que a leitura da primeira versão do "Baudelaire", intitulada "Paris no Segundo Império", lhe havia causado. A cautela com a qual expressa essa decepção sobre o texto do amigo não esconde a profunda divergência teórica que o levou a recusar a publicação desta primeira versão, que "reúne motivos, mas não os executa". * Para o teórico da música, "executar motivos" não era apenas uma exigência musical, mas também teórica, pois, tanto na música, quanto na teoria, os motivos não poderiam ser simplesmente "reunidos" sem dar-lhes o devido desenvolvimento.

Adorno não ignora que o reunir e colecionar, o versammeln $\mathrm{e}$ sammeln, em geral, possuía um significado particular para Benjamin e fazia parte do seu programa articulado nas Passagens: "Método deste trabalho: montagem literária. Não tenho nada a dizer. Somente a mostrar." Adorno sabe que a falta de "execução" dos motivos faz parte de uma "ascese" ou de uma "disciplina" de Benjamin, que consiste na renúncia a uma maior elaboração dos motivos ou ainda na renúncia à mediação entre eles. Mas, apesar de reconhecer o valor de tal procedimento para trabalhos menores e apesar de defendê-lo 20 anos mais tarde em "O ensaio como forma”, Adorno o considera, nesse momento, inadequado em um trabalho que viria a ser o "modelo em miniatura" de toda a "Obra das Passagens" e que tem a pretensão de operacionalizar conceitos marxistas.

$\mathrm{Na}$ verdade, o problema para Adorno não são as divergências teóricas, mas a falta de teoria ou de "execução" teórica, que se evidencia na exposição de fatos isolados ou, como ele diz na mesma carta, da "mera faticidade". . Dizendo que o texto sobre Baudelaire ficou aquém do seu próprio a priori, a saber, do materialismo dialético, Adorno resume sua crítica da seguinte maneira:

Permita-me de me expressar da maneira mais simples e hegeliana quanto possível. Se não me engano, falta uma coisa a essa dialética: 
a mediação [Vermittlung]. Em todo o trabalho predomina uma tendência de relacionar os conteúdos pragmáticos de Baudelaire imediatamente com traços contíguos da história social da época, preferencialmente, de ordem econômica.

Para Adorno, o materialismo benjaminiano não é dialético, porém imediato, sem mediação, quase antropológico e quase "romântico". É um materialismo que reúne ou coleciona seu material, sem estabelecer, mediante a teoria, relações com seu contexto histórico. A crítica de Adorno, entretanto, culmina numa defesa:

Com isso acredito ter tocado no centro da questão. O efeito que parte de todo o seu trabalho e que este surtiu não apenas em mim e na minha ortodoxia em relação às Passagens é que o Senhor nele se violentou [...] para pagar um tributo ao marxismo que não é vantajoso para este nem para o Senhor: não para o marxismo, pois a mediação com a totalidade do processo social foi omitida e foi atribuído, quase de maneira supersticiosa, à enumeração material um poder esclarecedor que é reservado exclusivamente à construção teórica, mas nunca à referência pragmática; esse tributo tampouco é vantajoso para a substância mais peculiar do Senhor quando proíbe a si mesmo seus pensamentos mais ousados e fecundos devido a uma espécie de pré-censura conforme categorias materialistas (que, de maneira alguma, coincidem com as marxistas).

Adorno defende Benjamin contra si mesmo, ou seja, contra uma "pré-censura", um superego supostamente marxista, pois, além de prender seus "pensamentos mais ousados e fecundos" numa camisa-de-força materialista, o materialismo usado por Benjamin como fundamento teórico também não é marxista, pelos menos aos olhos de Adorno.

Sabemos que Benjamin acaba escrevendo uma segunda versão que, ironicamente, ganhou o título "Sobre alguns motivos em Baudelaire" ("Über einige Motive bei Baudelaire”). Apesar do título, porém, Benjamin agora não se limita a "reunir alguns motivos" e fica visível o seu esforço de conferir um aspecto teórico ao seu texto, inserindo Baudelaire e sua obra na já experimentada dicotomia entre "experiência" e "vivência" e estabelecendo mediações com a obra de Proust, a filosofia de Bergson e a psicanálise de Freud. Adorno lê o texto "com entusiasmo", apontando como única ressalva "a adoção da teoria freudiana da memória enquanto proteção contra estímulos e sua aplicação a Proust e Baudelaire.”* Mas, mais uma vez, ele defende o amigo generosamente contra a própria ressalva quando, observando que o conceito de aura "ain-
"(Idem: 784-5.)

"(Idem: 786.)

(Idem: 787.)

"(BENJAMIN, W. Gesammelte Schriften. Vol. 1/3. Frank furt/M.: Suhrkamp, 1974 1991: 1130. Trad. nossa.)

"(Idem: 1131.) 
(Idem: 1132.) [“L'étude du beau est un duel où l'artiste crie de frayeur avant d'être vaincu."] (BAUDELAIRE, Charles. CEuvres complètes. Bibliothèque de la Pléiade. Paris: Gallimard, 1961: 232.)

(BENJAMIN, W. A Modernidade. Edição e tradução de João Barrento. Lisboa: Assírio \& Alvim, 2006: 113-4.) da não foi 'pensado até o fim' ['ausgedacht']": "Sou da convicção que os nossos melhores pensamentos são sempre aqueles que não conseguimos pensar totalmente."

Adorno, no entanto, deve ter passado por novas decepções quando Benjamin, depois de ter atendido as suas exigências quanto a uma maior mediação e depois de ter teorizado sobre a questão do choque em Freud, passa imediatamente, ou melhor, sem outra mediação a não ser a livre associação entre choque e susto, a citar a famosa frase de Baudelaire sobre o artista, que "antes de ser vencido, dá um grito, assustado"*

A passagem direta da temática do choque em "Além do princípio do prazer" para o texto "Le confiteor de l'artiste" é bastante questionável, pois o "poema em prosa" de Baudelaire simplesmente não tematiza os choques da metrópole. Mais questionável ainda, porém, pelo menos numa perspectiva "teórica", é a descrição subseqüente da pessoa de Baudelaire. Dando continuação ao motivo do duelo e do susto, e apoiando-se "nas declarações de muitos contemporâneos”, Benjamin prossegue:

Vendo-se assim entregue ao susto, é natural que Baudelaire o provoque também. Vallès deixou testemunho do seu jogo de feiçōes excêntrico; Pontmartin, baseando-se num retrato de Nargeot, chega à conclusão de que o rosto de Baudelaire foi confiscado; Claudel acentua o tom cortante que o caracterizava nas conversas; Gautier fala dos "espaçamentos" a que Baudelaire gostava de recorrer quando recitava poesia; Nadar descreve o seu andar abrupto.

Se a mediação entre a defesa contra os choques em Freud, os duelos do artista e a aparência de Baudelaire podem suscitar uma série de objeções, a justaposição da fisionomia, da voz e do andar do poeta com base no choque, visual ou sonoro, ou ainda: com base em tudo que é brusco ou repentino, deve ter causado novamente alguma decepção em Adorno, mesmo porque Benjamin, aparentemente, parece "argumentar" não apenas a partir de dados biográficos um tanto aleatórios e questionáveis, mas a partir de detalhes particulares que não costumam fazer parte de um estudo histórico ou sociológico.

Além disso, espera-se de um trabalho com pretensóes teóricas sobre o maior poeta francês do século XIX que sua obra seja analisada e usada como suporte para as afirmações feitas no ensaio. No entanto, apesar de citar constantemente os poemas das Flores do Mal e os poemas em prosa do Spleen de Paris, Benjamin não dialo- 
ga com a obra de Baudelaire no sentido de uma análise de sua linguagem e de outros recursos poéticos. Ele cita o poema "Le soleil" para estabelecer uma relação entre Baudelaire e seu amigo pintor Constantin Guys mediante a temática da esgrima, mas não comenta os versos "Tropeçando em palavras como na calçada, / Dando às vezes com versos há muito sonhados."*

Ao trabalho detalhado com a representação simbólica na obra Benjamin, prefere o detalhismo sensorial causado pelo aspecto físico do poeta. Parece que a inserção de citações está obedecendo mais ao já mencionado "método" da montagem literária, do que ao postulado tradicional da mediação entre a linguagem poética e seu significado para a totalidade da obra ou ainda a totalidade histórica. Sem diferenciar autor e eu lírico, Benjamin se preocupa mais em estabelecer analogias entre os choques recebidos e os choques causados pela pessoa de Baudelaire do que em procurar os reflexos desse ambiente "chocante" numa análise detalhada na obra do poeta.

Já na primeira versão do "Baudelaire", cuja publicação foi recusada por Adorno, Benjamin apresenta um procedimento semelhante: passando por cima das diferenças sociológicas e históricas, ele congrega conspiradores profissionais e não-profissionais, a figura de Napoleão III e o próprio Baudelaire para mostrar que todos eles têm uma relação pouco articulada com um grupo social cuja marca é a própria heterogeneidade, isto é, com a boêmia parisiense. Composto, segundo Marx e Engels, de "todo tipo de pessoas ambíguas", " esse grupo, de certa maneira, se caracteriza pela impossibilidade de ser caracterizado; trata-se de uma não-classe, pois seus membros escapam a qualquer classificação.

O critério negativo que reúne os membros da boêmia é seu caráter "saltitante" - uma tentativa de traduzir sprunghaft, termo que significa "aos saltos" e que abrange idéias como o imprevisível, o descontínuo, o brusco e o repentino, ou seja, tudo que não possui uma lógica ou coesão interna. Essa imprevisibilidade marca tanto a política de Napoleão III quanto os escritos teóricos de Baudelaire:

Durante o seu período imperial, Napoleão continuou com essas práticas conspirativas. Proclamações surpreendentes e secretismos, rompantes bruscos e ironia impenetrável fazem parte da razão de Estado do Segundo Império. E os mesmos traços se encontram nos escritos teóricos de Baudelaire. Aí, seus pontos de vista são quase sempre expostos de forma apodíctica. A discussão não é o seu forte.
" ["Trébuchant sur les mots comme sur les pavés, / Heurtant parfois des vers depuis longtemps rêvés."] (BENJAMIN, W. A Modernidade. Op. cit.:114.)

(BENJAMIN, W. Gesammelte Schriften. Vol. 1/2. Op. cit.: 513.)

- (BENJAMIN, W. A Modernidade. Op. cit.: 14) 
É curioso que Benjamin atribua "hábitos conspirativos" a duas figuras que simplesmente não atuaram como conspiradores militantes. A conspiração da qual ele fala se refere muito mais ao caráter imprevisível com que surpreendem seus contemporâneos do que à sua efetiva atuação política. Além disso, ao conhecedor de Benjamin não escapa que este, falando de Baudelaire, retrata a si mesmo, uma vez que o tom apodíctico faz parte do seu repertório. A própria "montagem", que consiste em justapor dois personagens tão distantes como Napoleão e Baudelaire, sugere uma certa afinidade com eles, pois o caráter inesperado dessa aproximação revela o "imediatismo" do próprio Benjamin e, assim, uma certa afinidade com eles, por mais que os critique no plano político.

Dando continuação à descrição de Baudelaire e de suas contradições nos seus escritos teóricos, Benjamin se torna mais claro ainda:

Por volta de 1850, [Baudelaire] proclama que a arte não se separa do que é útil; poucos anos mais tarde já defende a arte pela arte. Em tudo isto, Baudelaire preocupa-se tão pouco em justificar-se e argumentar perante o seu público como Napoleão III ao passar, do dia para a noite e ignorando o parlamento francês, do protecionismo para o livre-comércio.

É esclarecedor para o nosso contexto que o tradutor português usou dois verbos, justificar e argumentar, para traduzir um único termo alemão, que é Vermittlung, mediação. Baudelaire não se preocupa com qualquer mediação diante do seu público e, evidentemente, sua atitude política não é menos sprunghaft, "saltitante", que sua postura teórica, pois, segundo Benjamin, "sua expressão carece de lógica e os seus fundamentos são frágeis". " Cabe lembrar que a "expressão" (Ausdruck) faz parte do vocabulário particular de Benjamin, que, nas Passagens, chegou a sugerir que ela determinasse a relação entre infra-estrutura e superestrutura. ${ }^{*}$ De acordo com o original alemão, a expressão de Baudelaire é unvermittelt, sem mediação, o que, para Benjamin, já é um pleonasmo, pois a ausência de mediação define sua compreensão da "expressão".

É curioso que a montagem, enquanto mimese estética ou poética dos "saltos" através dos quais Benjamin procura representar o caráter "saltitante" de Baudelaire, não saltou também aos olhos de Adorno e Horkheimer. Desde o início da primeira versão, que causou tanta decepção nos dois, Benjamin parece ter-lhes deixado um "recado" quando aponta para a falta de mediação e as contradiçõos 
evidentes em Baudelaire, sinalizando assim que uma inserção do poeta numa lógica totalizante seria inadequada para uma época em que o indivíduo resiste à "mediação com a totalidade do processo social", para retomar as palavras de Adorno acima citadas.

Numa carta a Horkheimer, Benjamin havia tentado alertar antecipadamente seus amigos para seu procedimento não-teórico:

Permita-me de dizer através de uma imagem o que pretendo fazer: trata-se de mostrar Baudelaire, como ele se encaixa no século XIX [eingebettet liegt]. A impressão [Abdruck] que ele deixou nesse século tem que aparecer de uma maneira tão clara e intocada como a de uma pedra que, depois de permanecer no seu lugar durante décadas, foi removida dele.

Já sabemos que o "mostrar" benjaminiano possui uma qualidade própria, pois se define pela sua oposição ao "dizer". Fazendo parte da técnica da montagem, qualquer coisa "mostrada" se caracteriza pela falta de "dizeres" mediadores com os elementos vizinhos, mais exatamente, com os anteriores e posteriores. Como no caso do mosaico da Origem do drama barroco alemão, a montagem literária interrompe o fluxo do texto, impossibilitando assim uma mediação contínua. A própria impressão deixada pela pedra pode ser vista como imagem do imediato: trata-se de uma impressão [Abdruck] que, como seu antagonista, a expressão [Ausdruck], aponta para a ausência de qualquer mediação subjetiva. $\mathrm{O}$ papel do sujeito, nesse caso, se limitou à remoção da pedra.

Qualquer mediação teórica se baseia no esforço subjetivo de relacionar o particular com o todo, ou seja, a mediação acaba sendo uma imposição do sujeito. $\mathrm{O}$ choque que impede essa mediação e que perpassa como um leitmotiv os diversos motivos da segunda versão "autorizada" do trabalho, embora possa ser visto como instância mediadora, possui, ao mesmo tempo, um caráter negativo: quando Benjamin relaciona, mediante o choque, não apenas as manifestações físicas de Baudelaire, mas também Baudelaire e Napoleão III e, ainda, o comportamento da multidão, dos trabalhadores nas fábricas e dos jogadores de jogos de azar, ele reúne todos esses personagens e segmentos da sociedade sob o signo da perda da subjetividade. Retomando a dicotomia entre experiência e vivência Benjamin constata:

À vivência do choque que o transeunte tem no meio da multidão corresponde à "vivência" do operário junto da máquina. [...] [Baudelaire] sentiu-se fascinado por um processo em que o mecanismo
* (BENJAMIN, Walter. Briefe. Op. Cit.: 783.)

(BENJAMIN, W. Origem do drama barroco alemão. Tradução, apresentação e notas: Sérgio Paulo Rouanet. São Paulo: Brasiliense, 1984: 50-51.) 
(BENJAMIN, W. A Modernidade. Op. cit.: 129-130.)

(BENJAMIN, W. A Modernidade. Op. cit.:134.)

-(BENJAMIN, W. Passagens. Op.cit.: 381.)

(Idem: 378.) reflexo que a máquina desencadeia no operário pode ser estudado no ocioso como no espelho - o dos jogos de azar. [...] O movimento de sacão no fluir do processo mecânico corresponde, no jogo de azar, ao chamado lance. Cada uma das operaçôes do operário na máquina não tem qualquer relação com a anterior, porque é a sua exacta repetição. Na medida em que cada movimento executado na máquina se demarca do anterior como cada lance do jogo de azar em relação ao que o precedeu, a escravidão do operário assalariado é, a seu modo, o correspondente da escravidão do jogador. Ambas as formas de trabalho estão igualmente vazias de conteúdo.

Provavelmente, essa passagem é a que mais se coaduna com o a priori marxista do texto, pois não é difícil relacionar a passividade do operário de fábrica com os conceitos marxistas de reificação e alienação. Mas Benjamin, ao invés de alinhar suas reflexões a esses conceitos, se dedica muito mais a evidenciar que, apesar da aparente oposição entre o trabalhador e o jogador, isto é, alguém que não trabalha, ambos têm uma coisa em comum: o fato de suas ações não terem nenhuma relação com as ações anteriores ou posteriores. Os choques aos quais essas duas figuras são expostas e que lhes impõem um comportamento "reflexo" se refletem ao mesmo tempo através de "correspondências" mútuas.

Evidentemente, a referência - sempre em francês - às correspondances é uma evocação do poema homônimo de Baudelaire. Como no caso da descrição da pessoa de Baudelaire, onde fisionomia, voz e andar se correspondiam, no poema de Baudelaire, as diversas impressōes sensoriais entram numa relação sinestésica ("Les parfu$\mathrm{ms}$, les couleurs et les sons se répondent."), sem ter, no entanto, o homem como instância centralizadora. As correspondências são associadas ao infinito e se tornaram inalcançáveis para o homem.

Os comentários de Benjamin sobre o poema são vagos e logo vão além de seu conteúdo quando introduzem um elemento temporal. Partindo do pressuposto de que, com a perda da experiência, As Flores do Mal são dedicadas a "algo de irremediavelmente perdido", as vivências descritas não têm como corresponder a qualquer coisa que seja deste mundo. Nas Passagens, Benjamin chega a falar das correspondências entre Antigüidade e Modernidade que seriam "única concepção construtiva da história em Baudelaire", sendo que, mais uma vez, o critério que permite uma mediação entre as duas épocas é de ordem negativa: "O traço com que a modernidade se aparenta definitivamente e da maneira mais íntima à Antigüidade é seu caráter fugaz.”* 
Mesmo se Benjamin descobriu nos escritos teóricos alguma reflexão sobre o que poderia vir a ser o "conceito de correspondances" em Baudelaire, "este conceito se relaciona melhor com suas próprias reflexões feitas em "A doutrina das semelhanças" ou em seu ensaio sobre as Afinidades eletivas de Goethe, pois, semelhanças, afinidades e analogias apontam para um pensamento que privilegia a justaposição no espaço ao desenvolvimento seqüencial no tempo. Por outro lado, mesmo não podendo desenvolver esse conceito a partir de Baudelaire, nos moldes da mediação teórica, ele se aplica muito bem à sua pessoa: "A inquietude petrificada [erstarrte Unrube] é, aliás, a fórmula para a história de vida de Baudelaire, a qual não conhece desenvolvimento algum."*

Pensar "por correspondência" exige como primeira medida: que o fluxo do pensamento linear seja interrompido por "choques", pois são estes que, por mais destrutivos que sejam, fazem com que elementos anteriormente distantes se aproximem e possam ser cotejados como correspondentes. $\mathrm{O}$ conhecimento proporcionado por esse procedimento pode não atender às exigências de um desenvolvimento teórico, encontrando assim a resistência da academia, mas, pelo menos em alguns casos, convence até os seus representantes. O próprio Adorno se mostrou especialmente impressionado pela passagem sobre o jogador e suas correspondências com o operário de fábrica. ${ }^{*}$

Numa carta ao escritor e jornalista Alphonse Toussenel, que Benjamin qualifica como "extremamente notável", Baudelaire defende esse outro tipo de conhecimento que poderíamos chamar de "epistemologia poética":

O positivo é que você é poeta. Há muito tempo digo que o poeta é soberanamente inteligente... e que a imaginação é a mais científica das faculdades, porque só ela compreende a analogia universal, o aquilo que uma religiāo mística denomina correspondance. Mas quando quero imprimir essas coisas, dizem-me que sou louco.
- (BENIAMIN, W. A Modernidade. Op. cit.:134.)

"(BENJAMIN, W. Passagens. Op. cit: 374.$)$

"(BENJAmin, W. Gesammelte Schriften. Vol. 1/3. Op. cit.: 1130.)

"(BENJAMIN, W. Passagens. Op. cit.: 287.) 


\section{Georg Otte}

Possui mestrado em Letras Germânicas e Letras Românicas pela Universität Trier (1985), doutorado em Estudos Literários pela Universidade Federal de Minas Gerais (1994) e pós-doutorado pela Universidade Humboldt de Berlim (2004) . Atualmente é professor titular da Universidade Federal de Minas Gerais. É autor de vários artigos publicados no Brasil e no exterior, e co-organizou recentemente, com Sabrina Sedlmayer e César Guimarães, o livro $O$ comum e a experiência da linguagem (Belo Horizonte: Editora UFMG, 2007).

\section{Resumo}

Palavras-chave: Benjamin; Adorno; Baudelaire.

Key words: Benjamin; Adorno; Baudelaire.

Mots-clés: Benjamin; Adorno; Baudelaire.

A recusa de Adorno de publicar a primeira versão do texto de Benjamin sobre Baudelaire evidencia uma profunda divergência no pensamento e na escrita dos dois autores: enquanto Adorno exige o desenvolvimento linearmente desenvolvido dos temas teóricos, Benjamin resiste à mediação, substituindo-a por um princípio poético caro a Baudelaire: a correspondência.

\section{Abstract}

Adorno's refusal to publish the first version of Benjamin's text on Baudelaire puts in evidence a deep divergence in the thinking and writing of both authors: whereas Adorno demands the linearly mediated development of the theoretical themes, Benjamin resists mediation replacing it by a poetic principle dear to Baudelaire: the correspondence.

\section{Résumé}

Le refus d'Adorno de publier la première version du texte de Benjamin sur Baudelaire met en évidence une divergence profonde dans la pensée et dans l'écriture de ces deux auteurs: tandis qu'Adorno exige le développement par la médiation linéaire, Benjamin y résiste en la remplaçant par um principe poétique cher à Baudelaire: la correspondance. 